\title{
IDENTIFICAÇÃO DE OBJETOS DE INTERAÇÃO PARA APLICATIVOS DE COMÉRCIO ELETRÔNICO NA TV DIGITAL (COMÉRCIO TELEVISIVO)
}

\author{
Rosendy Jess Fernandez Galabo \\ Universidade Federal do Maranhão \\ rj@fgalabo.com \\ Carlos de Salles Soares Neto \\ Universidade Federal do Maranhão \\ csalles@deinf.ufma.br
}

\begin{abstract}
Resumo: O decreto 4.901 instituído pelo governo brasileiro tem, como dois dos seus objetivos, o incentivo na produção de instrumentos e serviços digitais e modelos de negócio para a TV digital. Uma das possibilidades para alcançar esses objetivos, está o comércio televisivo. Existem poucos aplicativos interativos para a TV digital brasileira, incluindo aplicativos de comércio televisivo. Uma das possíveis razões para essa reduzida quantidade de aplicativos são as poucas instruções para o design desses tipos de aplicativos. Dessa forma, o presente artigo visa identificar objetos de interação presentes em 12 interfaces de aplicativos de comércio televisivo de diferentes empresas e regiões do mundo através de um estudo analítico, para então agrupá-los conforme suas funções. O resultado obtido com esta pesquisa é um conjunto de objetos de interação que auxilia no design da interação de aplicativos de comércio televisivo, com a possibilidade de também guiar o design outros tipos aplicativos para TV digital.
\end{abstract}

Palavras-chave: Design de interação, Objetos de interação, Interface da TV digital, Aplicativos de TVDI, Comércio televisivo.

\begin{abstract}
The Brazilian governmental decree 4.901 has as two of its goals the production incentive of tools, digital services and business models for digital TV. One of possibilities to achieve these goals can be television commerce (t-commerce). There are few interactive applications for Brazilian digital TV, which include the t-commerce applications. One of the reasons for this reduced quantity of applications is the few instructions for designing Brazilian digital TV applications. In this way, this paper aims to identify interaction elements presented on twelve interfaces of $t$-commerce applications from different companies and countries around the world through analytical study, then grouping them according to their functions.
\end{abstract}


The result obtained is a set of interaction elements that assists on the interaction design of t-commerce applications, with the possibility to guide the design of different types of TV applications.

Keywords: Interaction Design, Interaction elements, Graphical user interface (GUI) elements, Digital Television Applications, Television commerce (t-commerce)

\section{INTRODUÇÃO}

A mudança da TV analógica para a TV digital (TVDi) vai além da melhor qualidade de imagem e de som. O novo sistema permite um número maior de possibilidades de interatividade, pois torna possível a transmissão de dados e assim expandir as funções do sistema na forma de aplicações (SOARES \& BARBOSA. 2012).

De acordo com dados do Panorama da Comunicação e das Telecomunicações de 2011/2012 realizada pelo IPEA (Instituto de Pesquisa Econômica Aplicada), no Brasil, a televisão alcança 5.565 munícipios e atinge 95,1\% dos domicílios. Segundo dados da Agência Nacional de Telecomunicações - ANATEL (2012), a cobertura da TV Digital já chega a $46,42 \%$ dos domicílios brasileiros. A presença da TV em quase toda residência brasileira e a mudança da TV analógica para a digital, possibilitará um maior acesso a informação e serviços para a população por meio de aplicações interativas.

Segundo Soares e Barbosa (2012), essas aplicações são programas computacionais armazenados em um dispositivo receptor ou transmissões de dados, enviados em conjunto com o áudio e vídeo principal por uma emissora de TV. Essas aplicações permitem a interatividade dos telespectadores e o surgimento de uma grande variedade de serviços, entre eles esta à possibilidade de comércio eletrônico.

Para Albertin (2010, p.3), o comércio eletrônico (e-commerce) pode ser definido como "a realização dos processos de negócio num ambiente eletrônico, por meio da aplicação intensa da tecnologia de comunicação e de informação." Os processos de negócio realizados na televisão digital é um caso particular de comércio eletrônico conhecido por comércio televisivo ou t-commerce.

De acordo com decreto 4.901 (DOU, 2003), o governo brasileiro instituiu objetivos para implantação do Sistema Brasileiro de Televisão Digital (SBTVD), entre elas estão: incentivar a indústria regional e local na produção de instrumentos e serviços digitais e estabelecer ações e modelos de negócios para a televisão digital adequado à realidade econômica e empresarial do País.

De acordo com dados do e-bit (2013), no primeiro semestre de 2013, houve um aumento na demanda de pedidos pelo e-commerce, um valor $24 \%$ maior do que o registrado no mesmo período. Com isso o número de consumidores virtuais também aumentou e a soma de pessoas que fizeram ao menos uma compra online no Brasil chega a 46,16 milhões. O Brasil é o primeiro país latino-americano a conseguir que as vendas online atingissem $1 \%$ do seu produto interno bruto (E-BIT 2012).

Dado esse cenário apresentado pelo Brasil, o comércio televisivo apresenta um considerável potencial para o mercado deste país. No entanto, é possível perceber a baixa quantidade de aplicativos, não só de comércio eletrônico, mas qualquer outro tipo de aplicativo interativo de TV. Uma proposta de comércio televisivo foi desenvolvida pela CERTI em parceria com a Brava ECM e financiada pela FINEP (Financiadora de Estudos e Projetos), uma empresa pública brasileira de fomento à 
ciência, e foi apresentada na 19a edição da Feira SET Broadcast \& Cable em São Paulo (DIALETTO, 2010) sendo então considerada a pioneira no desenvolvimento de um aplicativo de comércio televisivo.

Uma das razões que podem justificar essa baixa quantidade é a falta de instruções para o design de aplicações de TV digital. Entretanto, essa tecnologia já está presente em outros países, e a compreensão e identificação dos elementos utilizados em aplicativos interativos existentes nesse ambiente da TV pode contribuir para o desenvolvimento de aplicações semelhantes no Brasil.

Dessa forma, o objetivo dessa pesquisa é identificar objetos de interação utilizados em aplicativos existentes de comércio televisivo no mundo com intuito de reunir um conjunto de elementos que instruam o design de aplicativos de comércio televisivo através desses objetos, como também para uso em outros tipos de aplicativos para o ambiente da TV digital.

$O$ artigo tem a seguinte organização. A Seção 2 apresenta um referencial teórico sobre os objetos de interação. Na Seção 3 é descrita a metodologia da pesquisa. Os resultados da pesquisa são descritos na Seção 4. E por fim, na Seção 5, são apresentados as conclusões e os desdobramentos da pesquisa.

\section{OBJETOS DE INTERAÇÃO}

Os objetos de interação são elementos de software com recursos que reagem conforme as ações dos usuários sobre eles. Tais objetos presentes em um sistema interativo são metáforas de objetos do mundo digital e representam botões, menus, formulários de preenchimento etc (CYBIS et al., 2010).

De acordo com Tidwell (2010), os objetos de interação fazem parte de um vocabulário encontrado em diferentes interfaces de software. As interfaces de software possuem uma linguagem com um vocabulário próprio de objetos de interação, o que permite compreender e interagir com um artefato de software. No entanto, muitos vocabulários estão misturados entre outras linguagens de interfaces.

Cada linguagem de interface está relacionada com diferentes contextos de uso, enquanto que o paradigma tradicional do computador utiliza janelas, ícones e menus, a TV digital possui um ambiente que se difere do computador em diversas características (GALABO \& SOARES NETO, 2013). Por isso identificar os objetos presentes em aplicativos de comercio eletrônico no ambiente da TV se torna necessário para compreender uma linguagem através de objetos de interação para TV digital.

\section{METODOLOGIA DA PESQUISA}

A pesquisa utilizou o método de pesquisa analítica, no qual é um processo cognitivo que consiste em decompor o objeto estudado, separando cada uma das partes do todo (MARCONI \& LAKATOS, 2011) e visou identificar os objetos de interação utilizados em aplicativos de comércio televisivo.

A amostra coletada foi uma amostragem não probabilística, na qual foram selecionados por conveniência. O critério para a inclusão de interfaces de aplicativos de comércio televisivo foi à facilidade de acesso a esses aplicativos na Internet, no formato de imagens e vídeos de demonstração. Com isso, procurou-se formar um catálogo de aplicações abrangente e representativo, originados de pelos menos cinco países diferentes e de diversas empresas, conforme pode ser visto no Quadro 1 abaixo. 
Quadro 1 - Interfaces de aplicativos de comércio televisivo analisados na pesquisa

\begin{tabular}{|l|l|l|}
\hline Interface de comércio televisivo & Empresa / Emissora & Origem \\
\hline Brava tcommerce & Brava iTV & Brasil \\
\hline YuBuy Telepizza & YuBuy & Portugal \\
\hline Domino's Comércio televisivo & Sky & Reino Unido \\
\hline iCueTV tcommerce & iCueTV & Estados Unidos \\
\hline History Shop & History Channel & Estados Unidos \\
\hline HSN Shop by remote (AT\&T) & HSN & Estados Unidos \\
\hline HSN Shop by remote (Comcast) & HSN & Estados Unidos \\
\hline Rovi Advertising & Rovi Corporation & Estados Unidos \\
\hline This.co & Capstone media - This.co & Coréia do Sul \\
\hline CJ TMall & CJ O Shopping & Coréia do Sul \\
\hline
\end{tabular}

Fonte: Elaborado pelos autores, com base na pesquisa realizada.

Para efeito de ilustração, as telas das aplicações são representadas na Figura 1 a seguir.
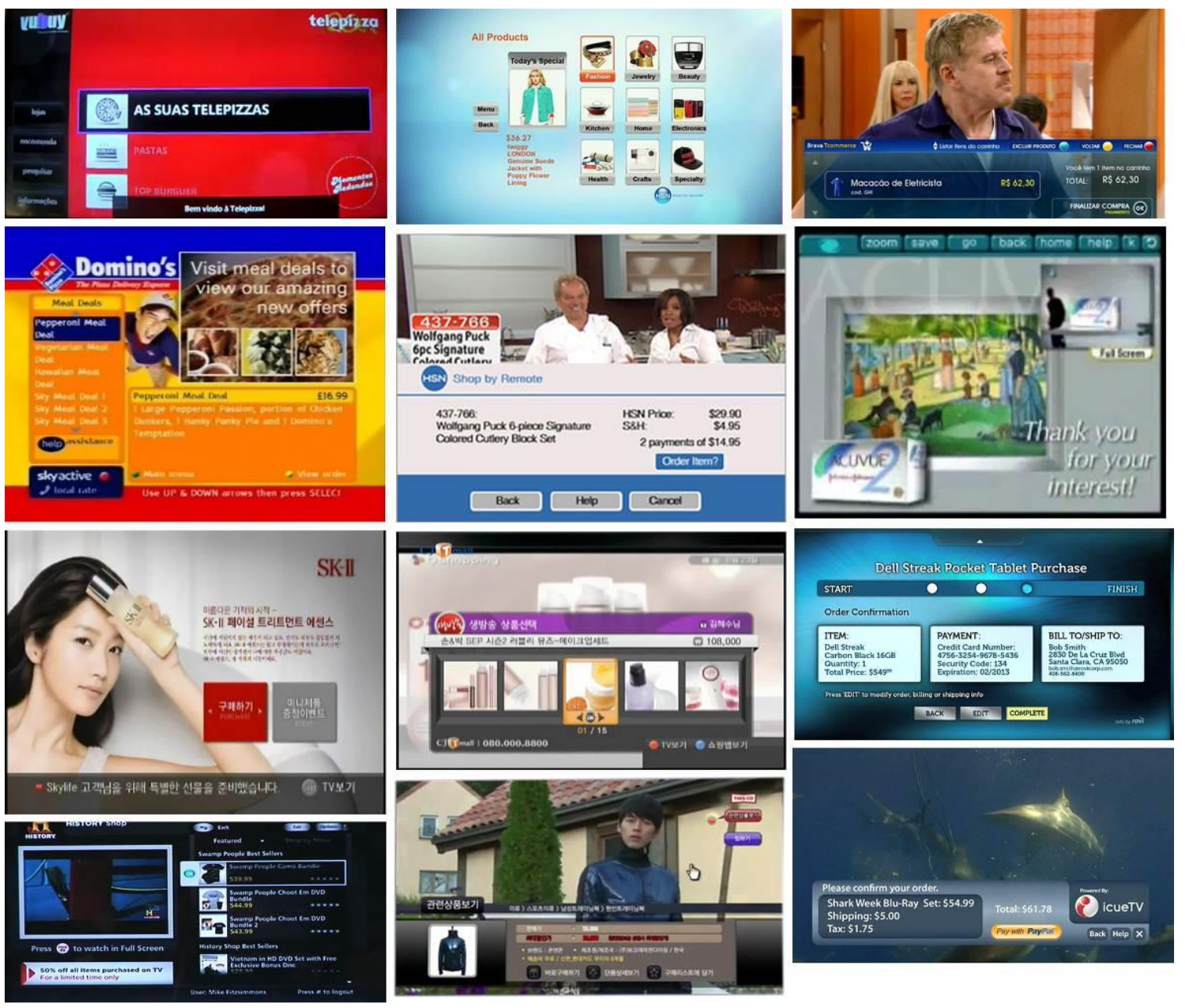

Figura 1 - Interfaces dos aplicativos analisados

Fonte: Elaborado pelos autores, com base na pesquisa realizada.

Os objetos de interação identificados foram analisados qualitativamente em relação às suas funções e, então agrupados de acordo com a natureza dos objetos de interação definidos por Cybis et al. (2010). 


\section{RESULTADOS DA PESQUISA}

Onze objetos de interação foram identificados nas diferentes aplicações e organizados de acordo com sua natureza dos objetos de interação no Quadro 2 abaixo.

Quadro 2 - Objetos de interações identificados em aplicativos de comércio televisivo

\begin{tabular}{|l|l|}
\hline Categoria & Objetos de interação \\
\hline Painéis de controle & - Mensagens / feedback \\
& - Breadcrumbs / Mapas de sequência \\
& - Teclado virtual \\
\hline Objetos para seleção & - Ícones de convite para interação \\
& - Menu de opções \\
& - Listas de seleção \\
& - Seletores de quantidade \\
& - Grupo de seletores exclusivos \\
& - Botões de comando \\
\hline Objetos para manipulação & - Cursor do controle remoto \\
\hline Objetos para edição & - Campos de dados \\
\hline
\end{tabular}

Fonte: Elaborado pelos autores, com base na pesquisa realizada.

Os painéis de controle são composições de objetos necessários para realização de uma ação ou tarefa; Os objetos para seleção facilitam a entrada de dados e comandos dos usuários por meio de várias opções disponíveis; Os objetos para manipulação representam a classe de objetos manipuláveis em uma interface gráfica; Os objetos para edição são uma classe de objetos que permite que os usuários entrem com valores não antecipáveis pelos desenvolvedores.

Ícones de convite para interação - Sete aplicações observadas apresentaram um ícone de convite para interação. Na Figura 2 são apresentados alguns desses exemplos.

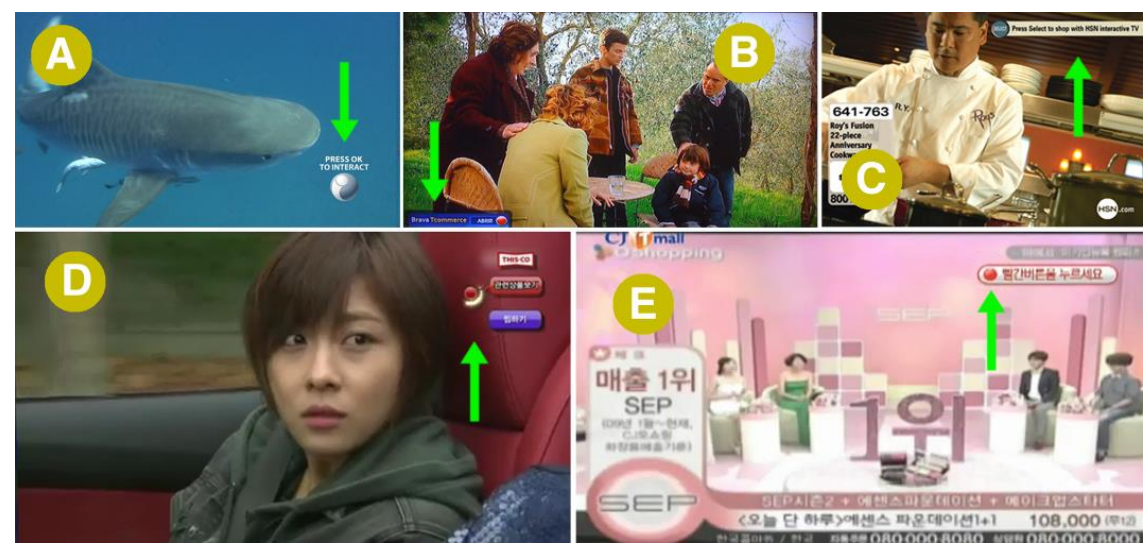

Figura 2 - Exemplos de ícones de convite para interação (A) IcueTV, (B) Brava Tcommerce, (C) HSN Shop by remote, (D) CJ Tmall e (E) This.co

Fonte: Elaborado pelos autores, com base na pesquisa realizada.

De acordo com Cybis et al. (2010) o convite à interação pode ser ativado automaticamente pelo sistema, ser uma reação do sistema de uma ação do usuário ou ser acionado explicitamente pelo usuário. Na TVDi, os ícones são apresentados ao usuário para informa a possibilidade de interagir com a TV por meio de uma aplicação e geralmente aparecem no canto da tela. Em comércio televisivo, esses ícones informam que a possibilidade de efetuar uma compra está disponível. 
Menus de opções foram identificados a presença dos menus em 6 das aplicações analisadas. A Figura 3 a seguir mostra alguns exemplos.
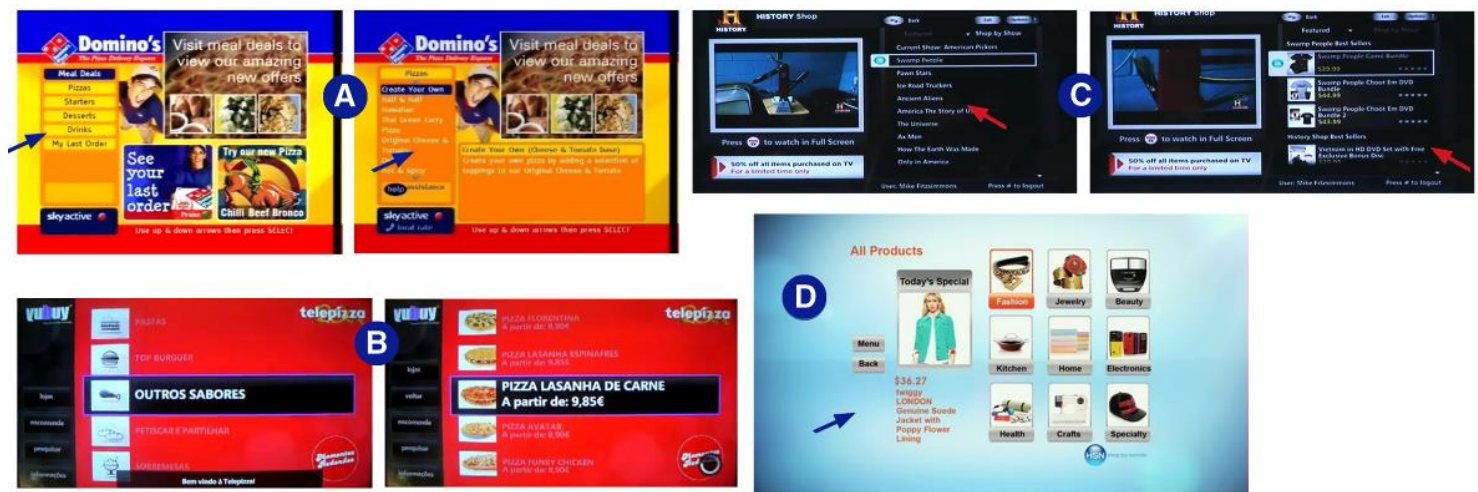

Figura 3 - Menu de opções: (A) Aplicativo Domino's; (B) Aplicativo YuBuy; (C) History Shop e (D) HSN Shop AT\&T

Fonte: Elaborado pelos autores, com base na pesquisa realizada.

Os menus de opções são objetos que permitem aos usuários a seleção de uma das opções disponíveis no sistema, podendo estas serem textuais ou composições gráficas. Em comércio televisivo, os menus de opções apresentam uma hierarquia estruturada na forma de categoria de produtos ou mesmo os próprios produtos.

O cursor do controle remoto está presente em todo o catálogo de aplicações. A Figura 4 abaixo mostra alguns exemplos encontrados.
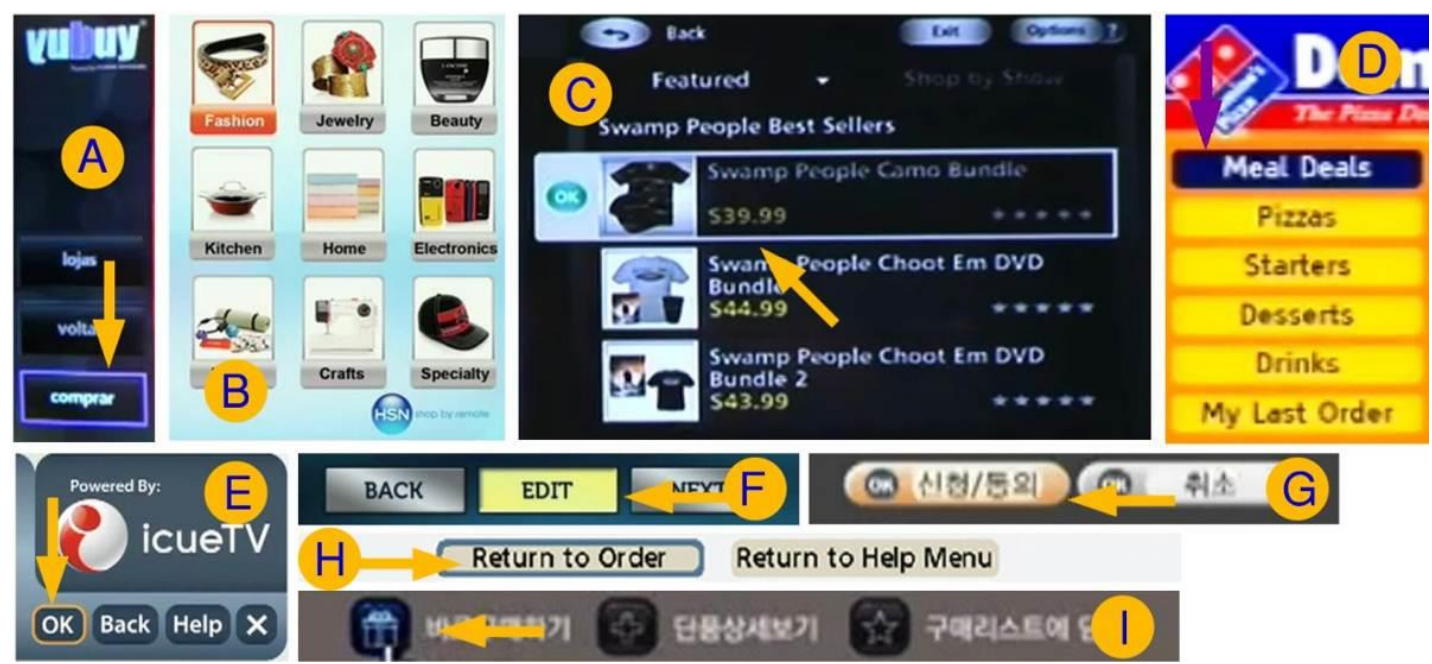

Figura 4 - Cursores: (A) Yubuy, (B) HSN Shop AT\&T, (C) History Shop, (D) Domino's, (E) IcueTV, (F) Rovi, (G) CJ TMall, (H) HSN Shop Comcast, (I) This.co

Fonte: Elaborado pelos autores, com base na pesquisa realizada.

O cursor do controle remoto seleciona e aciona parâmetros e funcionalidades dos diferentes objetos interativos na TV. Em comércio televisivo, o cursor seleciona e aciona os botões, os campos de dados, escolher os produtos ou serviços desejados e seleciona os caracteres nos teclados virtuais.

Os botões de comando estão presentes em todas as aplicações analisadas. Alguns exemplos de botões podem ser encontrados na Figura 5 a seguir. 

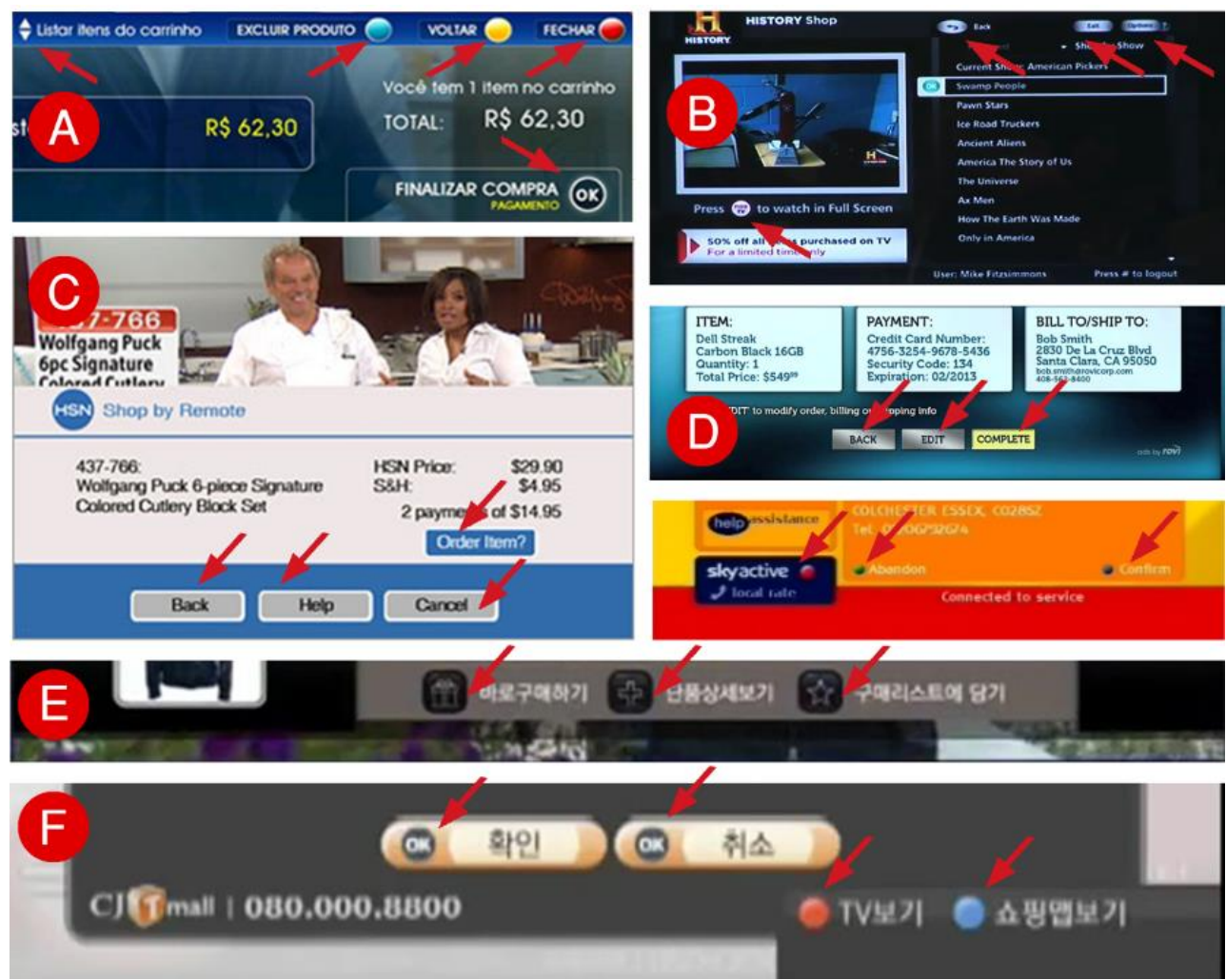

Figura 5 - Botões de commando: (A) Brava Tcommerce, (B) History Shop, (C) HSN Shop by remote Comcast, (E) This.co, (F) CJ TMall

Fonte: Elaborado pelos autores, com base na pesquisa realizada.

Os botões oferecem opções de comando para um sistema. Em interfaces de aplicativos de comércio televisivo, os botões podem ser selecionáveis com o cursor do controle remoto, apenas representar os próprios botões do controle remoto ou podem apresentar os dois tipos de interações. Esses botões oferecem os comandos de selecionar produtos, confirmar e voltar às etapas de compra, sair do aplicativo entre outros comandos existentes em comércio eletrônico.

O grupo de seletores foi encontrado em apenas uma aplicação do catálogo. A Figura 6 apresenta um exemplo desse objeto de interação.

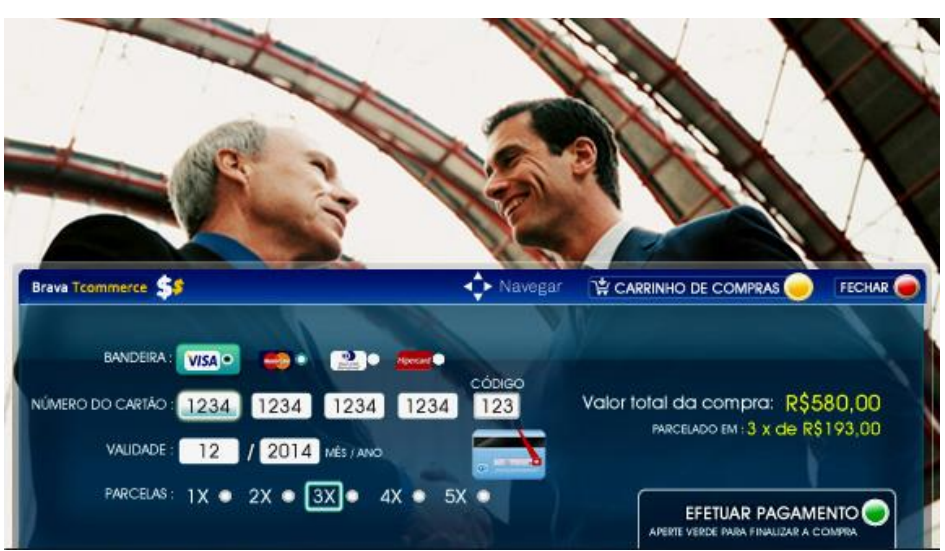

Figura 6 - Grupo de seletores exclusivos (radio button)

Fonte: Site da empresa Brava iTV ${ }^{1}$

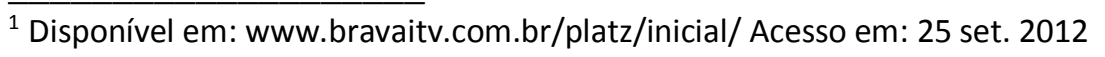


O grupo de seletor exclusivo é um recurso utilizado para tornar a entrada de dados mais rápida e segura. Tal objeto foi encontrado sendo utilizado como opções para um número de parcelas. No entanto, acredita-se ser possível o uso desse objeto de interação em outras ações da aplicação.

O teclado virtual foi encontrado em apenas uma aplicação entre as doze aplicações analisadas, o exemplo desse objeto é apresentado na Figura 7 a seguir.

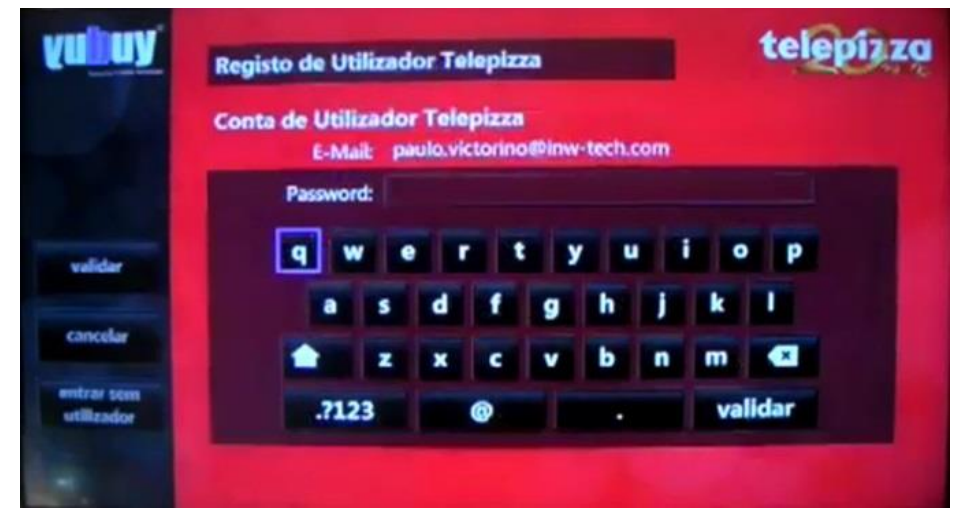

Figura 7 - Teclado virtual no Yubuy

Fonte: Youtube ${ }^{2}$

Esse objeto de interação é semelhante ao teclado convencional de computador e funciona utilizando o cursor do controle remoto para selecionar os caracteres desejados e o botão OK para inserir o caractere. No comércio televisivo esse objeto pode ser encontrado para cadastro ou para identificação do usuário (login).

Os campos de dados foram encontrados em todas as aplicações de comércio televisivo analisadas. Alguns exemplos podem ser vistos a seguir (Figura 8).
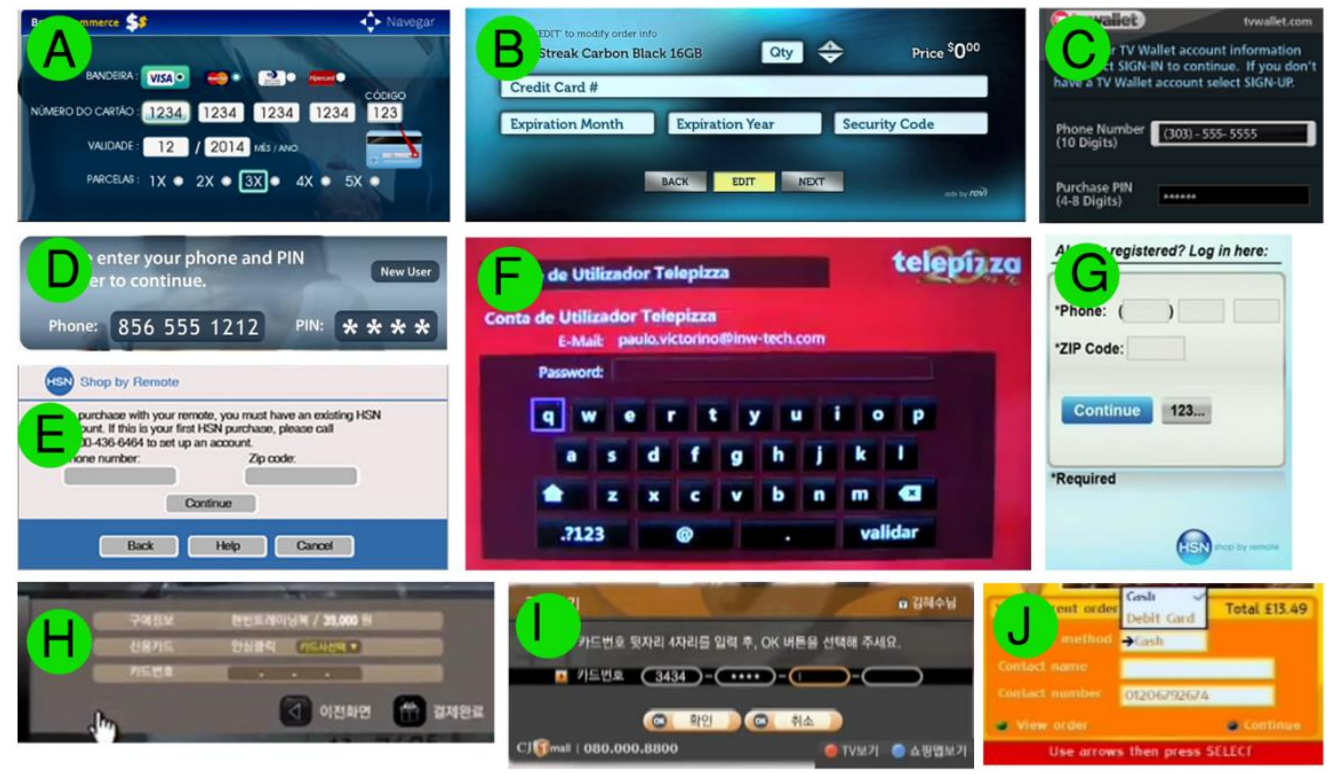

Figura 8 - Campos de dados: (A) Brava Tcommerce, (B) Rovi, (C) History Shop, (D) IcueTV, (E) HSN Shop by remote Comcast, (F) YuBuy, (I) CJ Tmall e (J) Domino's

Fonte: Elaborado pelos autores, com base na pesquisa realizada.

\footnotetext{
${ }^{2}$ Disponível em: www.youtube.com/watch?v=pb6U-mXJs54
} 
Esses objetos de interação permitem aos usuários a entrada de valores não antecipáveis pelos projetistas e está bastante sujeita a erros (CYBIS et al., 2010). Em comércio televisivo, a entrada de valores nos campos de dados é referente aos dados de cartão de crédito, senhas, CEP, número de telefone ou outros dados que contenham caracteres numéricos. Algumas interfaces necessitam o preenchimento de caracteres alfanuméricos, e nesse caso optam-se pelo uso de teclado virtual.

As listas de seleção foram identificadas em dois aplicativos do catálogo de aplicativos de comércio televisivo. Os exemplos desses objetos são apresentados na Figura 9 abaixo.
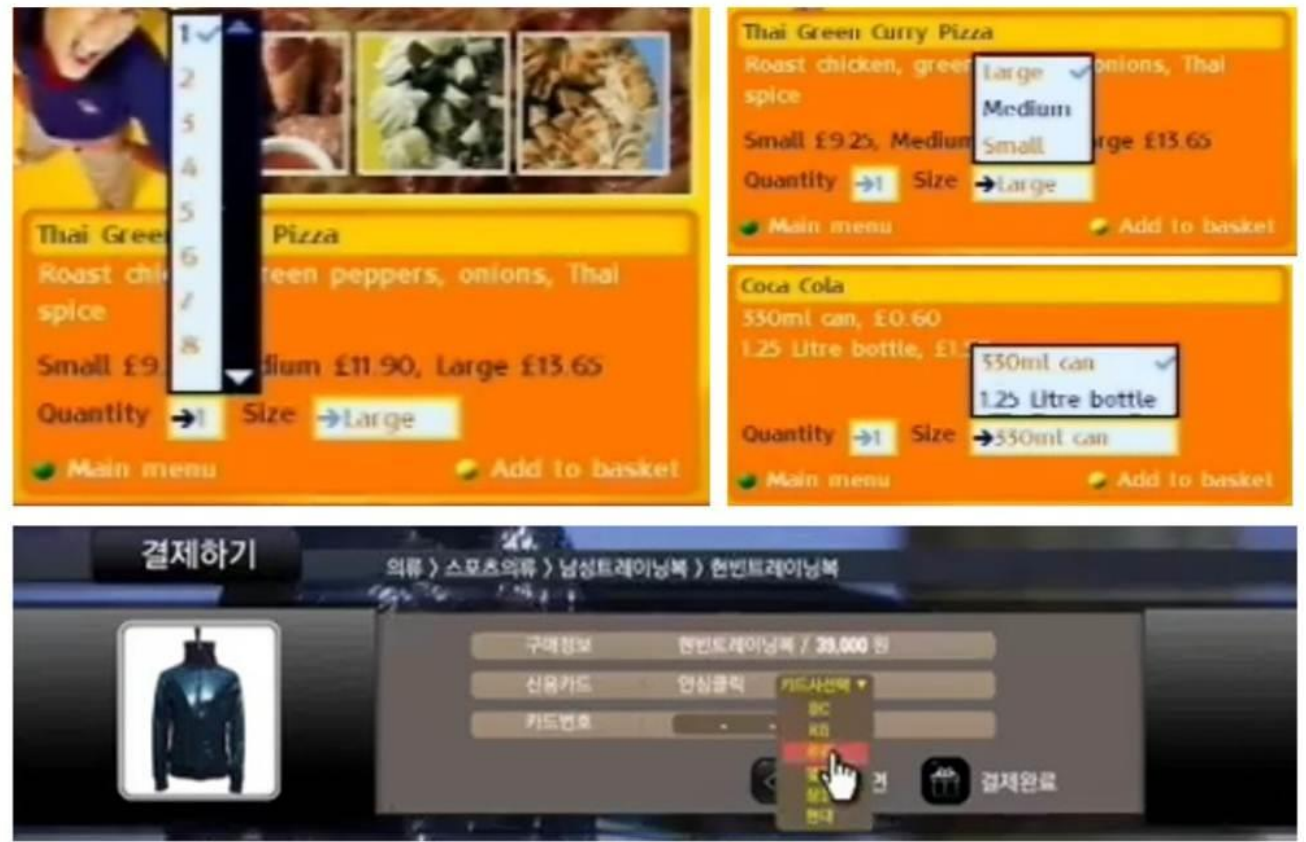

Figura 9 - Listas de seleção: Aplicativo Domino's (parte superior) e This.co (parte inferior) Fonte: Elaborado pelos autores, com base na pesquisa realizada.

A lista de seleção é composta por um conjunto de valores possíveis como entrada de dados feitos pelos usuários (CYBIS et al. 2010). Em comércio televisivo esses valores podem ser encontrados na forma de números, nomes de produtos, cartões conforme pode ser visto na Figura 9.

Os seletores de quantidade foram encontrados em sete aplicações do catálogo. A Figura 10 apresenta exemplos desse tipo de objeto de interação.
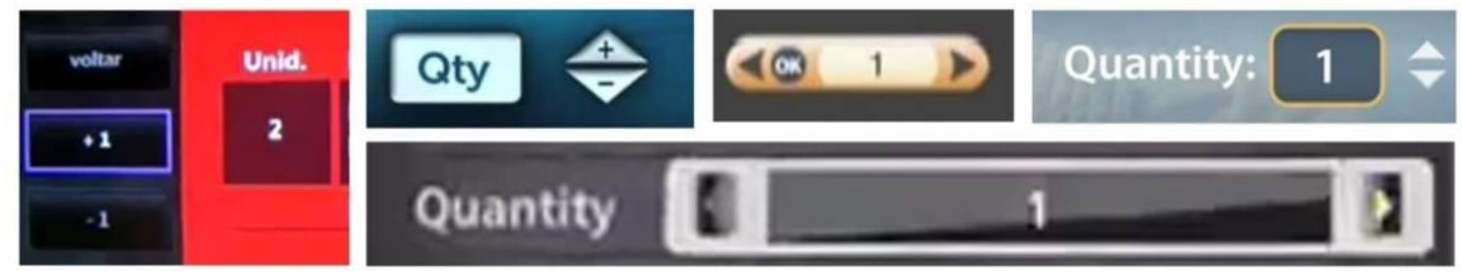

Figura 10 - Seletores de quantidade: YuBuy, Rovi, CJ Tmall, IcueTV, HistoryShop

Fonte: Elaborado pelos autores, com base na pesquisa realizada.

Os seletores de quantidade possibilitam a escolha de caracteres numéricos de forma limitada ou ilimitada utilizando se os botões direcionais do controle remoto para 
aumentar ou diminuir o valor apresentado. Em comércio televisivo, tal objeto de interação é utilizado para selecionar a quantidade de um produto desejado.

As mensagens e feedbacks foram encontrados em todo o catálogo de aplicativos. Alguns exemplos desses objetos podem ser vistos na Figura 11.
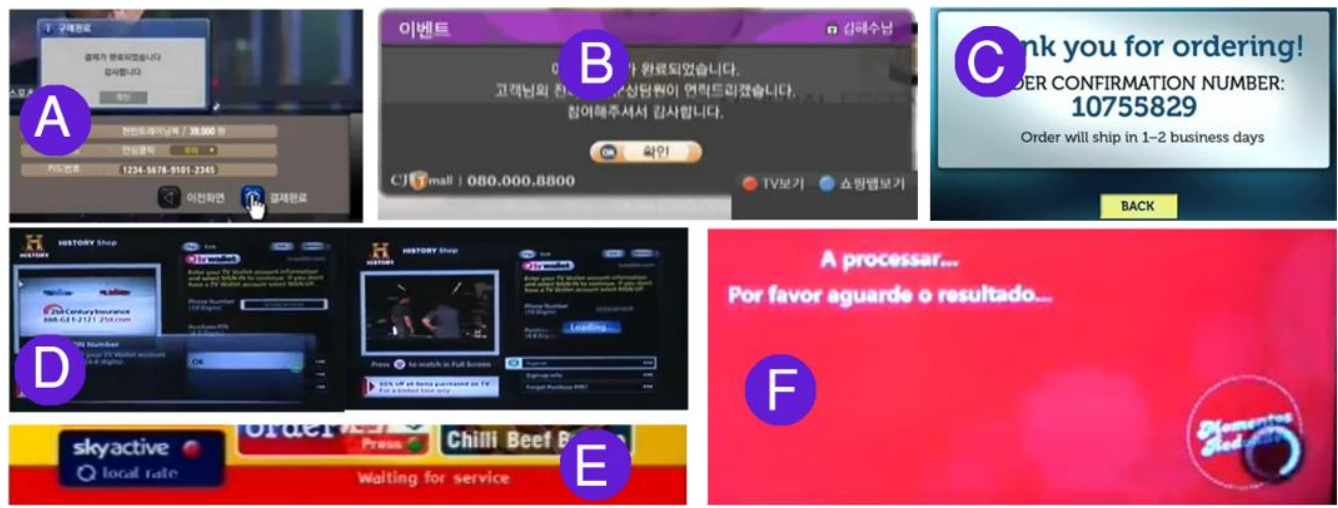

Figura 11 - Mensagens/Feedback: (A) This.co, (B) CJ Tmall, (C) Rovi, (D) History Shop, (E) Domino's, (F) Yubuy

Fonte: Elaborado pelos autores, com base na pesquisa realizada.

As mensagens podem ser apresentadas dentro de caixas de mensagem ou diretamente em áreas especiais nas telas e são usadas para orientar, ajudar, avisar, alertar ou sinalizar um erro ao usuário. Em comércio televisivo, as mensagens são utilizadas como forma de sinalizar os erros de identificação, falta de dados, de orientar sobre o próximo passo ou informar conclusão de compra.

Os feedbacks informam o usuário sobre o estado do sistema e podem ser um sinal sonoro ou um indicador de progressão (CYBIS, BETIOL e FAUST, 2010). Em comércio televisivo, os feedbacks informam a resposta da comunicação com as operadoras de cartão de crédito e outras formas digitais de pagamento, informam a conexão do usuário com o sistema de comércio televisivo e a conclusão do pedido do usuário.

Os breadcrumbs foram encontrados em um aplicativo e mapas de sequência em três aplicativos. A Figura 12 abaixo apresenta esses objetos.

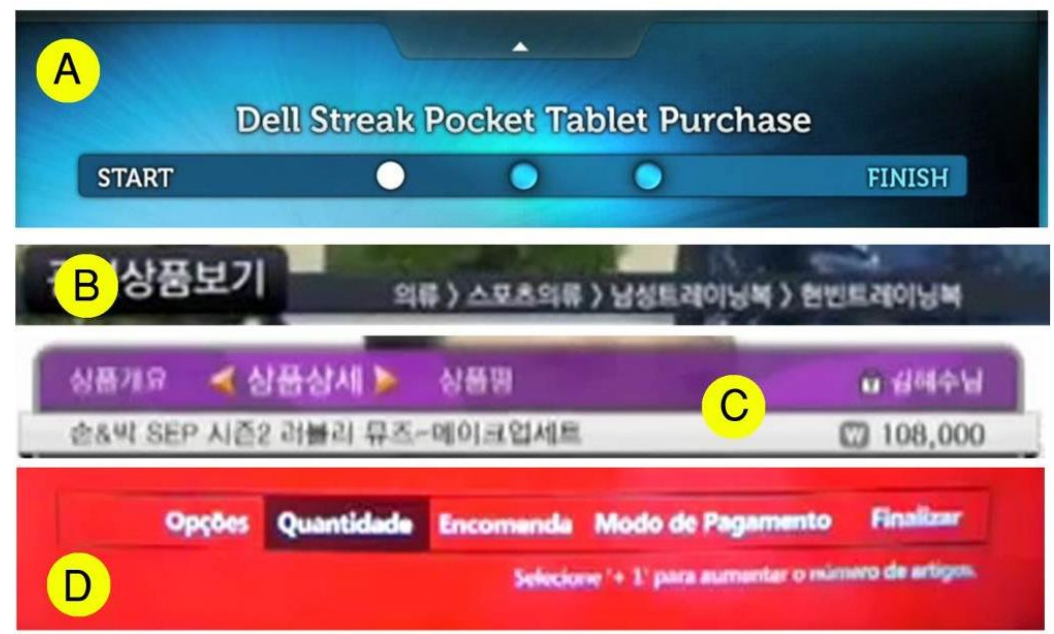

Figura 12 - Mapas de sequência: (A) Rovi, (C) CJ Tmall, (D) Yubuy e Breadcrumb em (B) This.co Fonte: Elaborado pelos autores, com base na pesquisa realizada. 
Os mapas de sequência informam o usuário sobre o caminho percorrido em um sistema e o quanto ele ainda tem que percorrer antes de ele terminar. Sabendo disso o objeto ajuda a decidir se o usuário quer continuar, estimar quanto tempo vai demorar e manter-se orientado. Já os breadcrumbs ou trilhas de migalha de pão mostram uma hierarquia no mapa do sistema e auxiliam o usuário a se localizar (TIDWELL, 2010).

Os breadcrumbs e os mapas de sequencia auxiliam na localização do usuário em um sistema. A diferença entre os dois é que os breadcrumbs não informam o passo seguinte (TIDWELL, 2010).

Em comércio televisivo, os mapas de sequência são apresentados com informações sobre o processo de compra e os breadcrumbs, auxiliam na orientação do usuário entre as categorias de produtos percorridas.

Em resumo, o conjunto de objetos de interação encontrados no comércio televisivo são apresentadas no quadro a seguir, conforme a sua categoria e uma breve descrição de cada função dos objetos de interação.

Quadro 3 - Objetos de interações em aplicativos de comércio televisivo e suas funcionalidades

\begin{tabular}{|c|c|c|}
\hline Categoria & Objetos de interação & Função \\
\hline \multirow[t]{3}{*}{$\begin{array}{l}\text { Painéis de } \\
\text { controle }\end{array}$} & Mensagens / feedback & $\begin{array}{l}\text { Sinalizar os erros de identificação, falta de dados, de } \\
\text { orientar sobre o próximo passo ou informar } \\
\text { conclusão de compra. }\end{array}$ \\
\hline & $\begin{array}{l}\text { Breadcrumbs / Mapas de } \\
\text { sequência }\end{array}$ & $\begin{array}{l}\text { Apresentar informações sobre o processo de } \\
\text { compra / Orientar a organização da categoria de } \\
\text { produtos }\end{array}$ \\
\hline & Teclado virtual & $\begin{array}{l}\text { Possibilitar a entrada de dados para cadastrar ou } \\
\text { para identificar um usuário (login) }\end{array}$ \\
\hline \multirow[t]{6}{*}{$\begin{array}{l}\text { Objetos para } \\
\text { seleção }\end{array}$} & Ícones de convite para interação & $\begin{array}{l}\text { Informar o telespectador que a possibilidade de } \\
\text { efetuar uma compra está disponível. }\end{array}$ \\
\hline & Menu de opções & $\begin{array}{l}\text { Apresentar uma hierarquia estruturada na forma de } \\
\text { categoria de produtos ou mesmo os próprios } \\
\text { produtos para o usuário. }\end{array}$ \\
\hline & Listas de seleção & $\begin{array}{l}\text { Apresentar um conjunto de valores possíveis na } \\
\text { forma de números, nomes de produtos e cartões de } \\
\text { crédito. }\end{array}$ \\
\hline & Seletores de quantidade & Selecionar a quantidade de um produto desejado \\
\hline & Grupo de seletores exclusivos & Facilitar a entrada de dados. \\
\hline & Botões de comando & $\begin{array}{l}\text { Oferecer comandos para selecionar produtos, } \\
\text { confirmar e voltar às etapas de compra, sair do } \\
\text { aplicativo entre outros comandos existentes em } \\
\text { comércio eletrônico. }\end{array}$ \\
\hline $\begin{array}{l}\text { Objetos para } \\
\text { manipulação }\end{array}$ & Cursor do controle remoto & $\begin{array}{l}\text { Selecionar e acionar os botões, os campos de } \\
\text { dados, escolher os produtos ou serviços desejados e } \\
\text { selecionar os caracteres nos teclados virtuais. }\end{array}$ \\
\hline $\begin{array}{l}\text { Objetos para } \\
\text { edição }\end{array}$ & Campos de dados & $\begin{array}{l}\text { Permitir a entrada de valores nos campos de dados } \\
\text { referente aos dados de cartão de crédito, senhas, } \\
\text { CEP, número de telefone ou outros dados que } \\
\text { contenham caracteres numéricos ou alfanuméricos. }\end{array}$ \\
\hline
\end{tabular}

Fonte: Elaborado pelos autores, com base na pesquisa realizada.

\section{CONCLUSÃO}

Através dos objetos de interação identificados pelo estudo (método) analítico de um catálogo de aplicativos de comércio televisivo. Foi possível organizar um 
conjunto de objetos que podem ser utilizados conforme a necessidade no design de uma aplicação ou protótipo de comércio televisivo.

Os objetos interativos identificados foram categorizados conforme as necessidades de ações de um usuário em um sistema, e representam a possibilidade de controlar, selecionar, editar e manipular aplicativos de comércio televisivo. É importante ressaltar que tais objetos podem ser utilizados em outros tipos de aplicativos, não somente em aplicativos para o comércio eletrônico na TV.

Além disso, foram identificadas diversas formas de interação em uma mesma categoria de objeto de interação. Como trabalhos futuros, é possível medir a usabilidade de cada objeto de interação em protótipos de comércio televisivo, como também obter as vantagens e desvantagens de cada microinteração entre os objetos de interação encontrados. Outra discussão possível está em como os resultados desta pesquisa podem ser integrados em um processo de desenvolvimento de aplicativos para a TVDi.

\section{REFERÊNCIAS}

ALBERTIN, Alberto Luiz; Comércio eletrônico: modelo, aspectos e contribuições de sua aplicação. 6 ed. São Paulo: Atlas. 2010.

ANATEL. 2012. Cobertura da TV Digital. Agência Nacional De Telecomunicações Disponível em <

http://www.anatel.gov.br/Portal/verificaDocumentos/documento.asp?numeroPublica cao $=258272 \&$ pub=orig. $>$. Acesso em: 9 ago. 2013

CYBIS, W. et. al. Ergonomia e Usabilidade: conhecimentos, métodos e aplicações. 2. ed. São Paulo: Novatec Editora, 2010.

DIALETTO. T-Commerce será um dos destaques da SET Broadcast \& Cable 2010. 2010. Disponível em <http://www.dialetto.com.br/site/t-commerce-sera-um-dos-destaquesda-set-broadcast-cable-2010/>. Acesso em: 25 de abril de 2014.

DOU. DECRETO № 4.901, DE 26 DE NOVEMBRO DE 2003. Institui o Sistema Brasileiro de Televisão Digital - SBTVD, e dá outras providências. Diário Oficial da União.

E-BIT. Webshoppers 27ạ edição. E-bit empresa \& Camara brasileira de Comércio Eletrônico. São Paulo, p.1-41. 2012

E-BIT. Webshoppers 28a edição. E-bit empresa \& Camara brasileira de Comércio Eletrônico. São Paulo, p.1-46. 2013

GALABO, R. J.; SOARES NETO, C. S.; Orientações para o design de interface e interação em aplicativos de comércio televisivo. Anais do 13ㅇ USIHC: Universidade Federal de Juiz de Fora - UFJF. 2013

IPEA. Panorama da comunicação e das telecomunicações no Brasil. Brasília: IPEA Instituto de Pesquisa Econômica Aplicada. 2011.

MARCONI, M.; LAKATOS, E. M. Metodologia científica. 6.ed. São Paulo: Atlas, 2011. $314 p$.

SOARES, L, F, G.; BARBOSA, S. D. J. Programando em NCL 3.0. Rio de Janeiro: Elsevier, 2012.

TIDWELL, J. Designing interfaces. 2 ed. Sebastpool: O’Reilly Media, Inc. 2010. 